\title{
MISTURAS ASFÁLTICAS AUTORREGENERATIVAS: ESTADO DA ARTE
}

\author{
V. Bacca Couto Joenck ${ }^{1}$; J. Villena ${ }^{2}$ \\ ${ }_{1,2}$ Universidade Federal do Paraná - UFPR, Av. Cel. Francisco H. dos Santos, 420-456, Jd. das Américas, \\ Curitiba/PR \\ vanessa.bacca@gmail.coml, joevillena@gmail.com²
}

Resumo: Este artigo tem por objetivo apresentar o estado da arte do desenvolvimento de novas misturas asfálticas autorregenerativas. As misturas asfálticas autorregenerativas são materiais asfálticos capazes de fecharem as trincas oriundas de tensóes de fadiga, incrementando a vida de serviço do pavimento e dispensando a remoção da camada de revestimento asfáltico. No Brasil, o tema ainda não ganhou destaque nas publicaçôes acadêmicas em razão de existirem pesquisas relacionadas com o tema ainda em desenvolvimento. No presente trabalho foi realizado um levantamento dos últimos artigos publicados em revistas internacionais e das principais contribuiçôes de pesquisadores. Assim, são apresentados os métodos que permitem baixar a viscosidade do ligante asfáltico de misturas aplicadas em campo a fim de acelerar o processo e o nível de autorregeneração. Por fim, este artigo propôs uma série de recomendaçóes para pesquisas futuras a fim de aprimorar o desenvolvimento destes tipos de misturas.

Palavras-chave: Misturas asfálticas autorregenerativas, Fadiga, Indução eletromagnética, Micro-ondas, Microcápsulas.

Abstract: This article aims to present the state of the art of new self-healing asphalt mixes development. The self-healing asphalt mixes are materials able to closing cracks from fatigue stresses by themselves, increasing pavemEnet life service and sparing the asphalt pavement removal. In Brazil, the issue has not yet gained prominence in academic publications due to the existence of research related to the topic still being developed. In this research, a survey of the last articles published in international journals and the contributions of the researchers regarding the subject was made. Thus, this article presents methods that allow reducing the constructed asphalt binder viscosity, in order to accelerate the self-healing process. Finally, this article proposes a set of recommendations for future researches in order to improve the development of these types of mixes.

Keywords: Self-healing of asphalt mixes, Fatigue, Induction heating, Microwave, Microcapsules. 


\section{Introduçáo}

As trincas em revestimentos asfálticos requerem manutenção imediata a fim de impedir a progressão da deterioração do pavimento. As trincas por fadiga originam-se da repetição de tensôes inferiores àquelas de ruptura gerada pelo tráfego de veículos, mas que com passar do tempo altera a estrutura interna do pavimento formando microfissuras progressivas que culminam no desenvolvimento de fraturas e consequentemente, no rompimento do material [1]. $\mathrm{O}$ trincamento por fadiga, quando em estágio muito avançado, também é conhecido como "couro de jacaré" (Figura 1), o qual comumente se encontra nas trilhas de rodas [2].

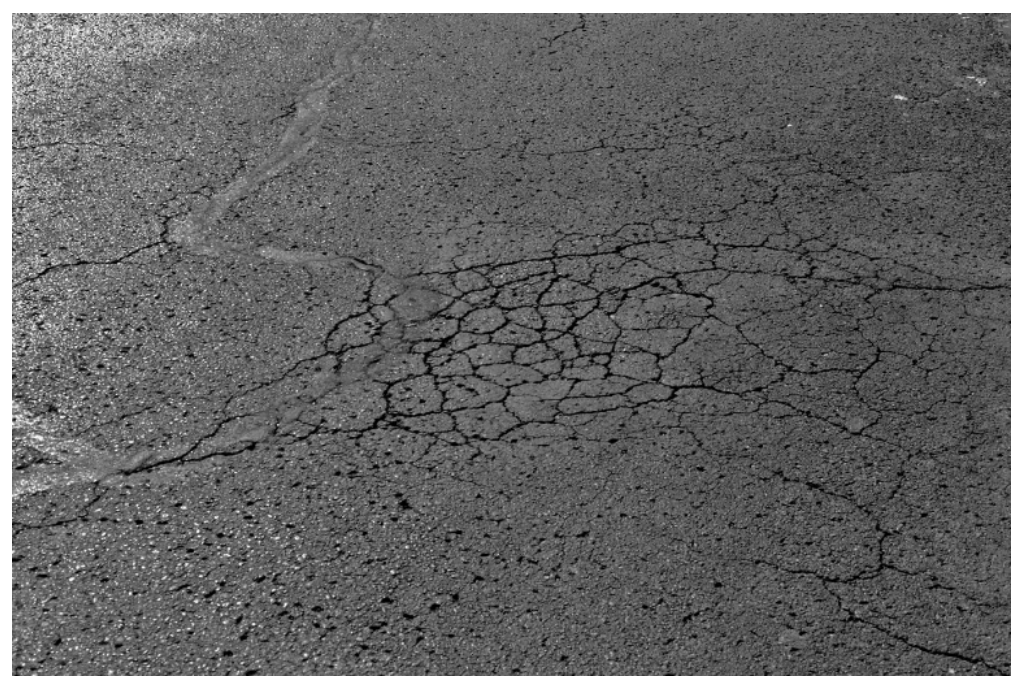

Figura 1 - Trincamento por fadiga em revestimento asfáltico [1]. Fonte: Adaptado [3]

As trincas em revestimento asfáltico são prejudiciais ao pavimento por diversas razóes, pois elas reduzem as propriedades mecânicas e diminuem a durabilidade ao permitir a entrada da água na estrutura, a qual acarreta a aceleração da deterioraçáo. A reabilitação do revestimento trincado usualmente é realizada por remoção do revestimento danificado e aplicação de uma nova mistura, o que implica em gastos econômicos, produçáo de novas misturas e dano ambiental por utilizar novos recursos. No Brasil a Pesquisa CNT de Rodovias 2016 [4] fez um levantamento de 103,3 mil km pavimentados e verificou que a qualidade de $48,3 \%$ do pavimento é considerada regular a péssimo, ou seja, são 50 mil km entre regular a péssimo, conforme apresentado na Figura 2. 


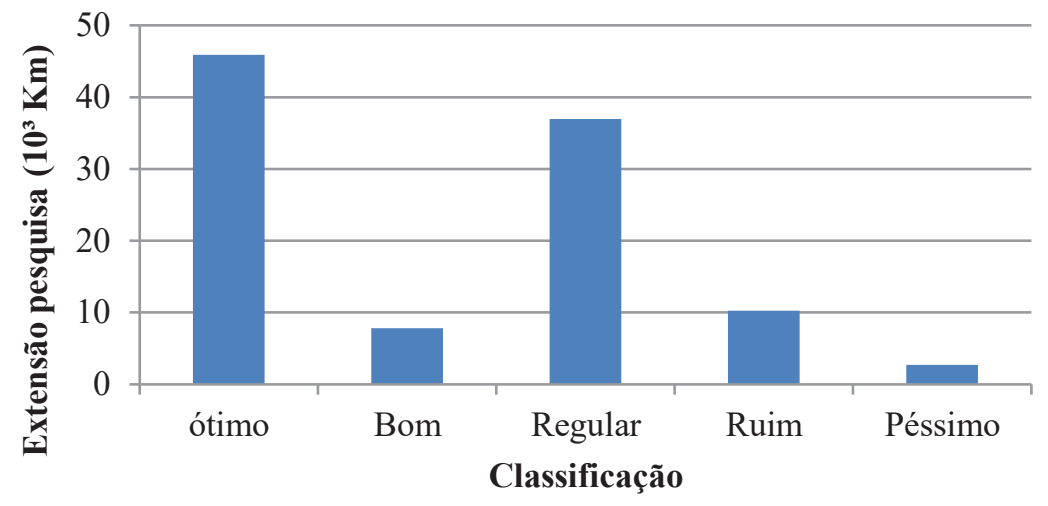

Figura 2 - Classificação dos $103.259 \mathrm{~km}$ de pavimento no Brasil. Fonte: Adaptado [4].

Nos pavimentos asfálticos, retardar a manutenção significa menor produção de concreto betuminoso, o que representa menores quantidades de emissóes de gases poluentes das usinas, economia de energia, além da menor necessidade de cimento asfáltico, de agregados pétreos e de areia, reduzindo detonaçóes e desmatamentos nas jazidas de exploração. Dessa forma, muitos pesquisadores têm buscado técnicas de manutenção que reciclam o material, sem a necessidade de utilizar novos materiais e remoção do revestimento trincado. A atual técnica refere-se ao desenvolvimento de misturas asfálticas autorregenerativas que têm a capacidade de se recuperarem de pequenas trincas oriundas das tensôes de fadiga, incrementando a vida de serviço do pavimento.

O presente estudo tem por objetivo realizar uma pesquisa bibliográfica com intuito de levantar as principais descobertas e resultados obtidos até o momento com relação ao desenvolvimento de misturas asfálticas autorregenerativas de trincas de tensóes de fadiga. Este artigo pretende, também, dar a conhecer este tema no Brasil e permitir servir de referência para subsidiar futuros estudos.

\section{Autorregeneração das misturas asfálticas}

Não há uma definição exata da capacidade de autorregeneração nos revestimentos asfálticos. Entretanto, a autorregeneração é entendida como uma resposta intrínseca do ligante asfáltico para reduzir as trincas dentro do corpo betuminoso, e consequentemente iniciar a recuperação parcial das propriedades originais do material asfáltico [5]. Uma limitação da autorregeneração é que a mesma náo é capaz de recuperar danos por deformação permanente.

O processo de autorregeneração não é perpétuo e a sua eficiência é afetada pela magnitude do dano sofrida pela mistura asfáltica. Neste sentido, [6] concluíram que quando as tensóes de fadiga reduzem em $60 \%$ o módulo de resiliência inicial, a recuperação da vida de fadiga é reduzida significativamente. Da mesma forma, [7] observaram em um experimento que misturas asfálticas de concreto asfáltico denso que sofreram redução em $70 \%$ do módulo de resiliência original, a regeneração 
alcançada foi baixa em razão da deformação permanente ou quebra dos agregados. Ainda, de acordo com [8] a autorregeneração apenas recupera trincas até uma determinada largura.

A autorregeneração em misturas asfálticas ocorre em períodos sem tráfego e em alta temperatura, especificamente entre $30^{\circ} \mathrm{C}$ a $70^{\circ} \mathrm{C}$, dependendo do tipo de ligante utilizado [8]. Entretanto, a autorregeneração é muito lenta em temperatura ambiente e é maior quanto maior o tempo de repouso entre as passagens de cargas [6]. Todos os autores estudados coincidem que o aquecimento do material por meio de uma fonte de energia externa é uma forma de acelerar o processo de auto regeneraçáo artificialmente. $\mathrm{O}$ aquecimento de misturas asfálticas usualmente é realizado por ondas eletromagnéticas ou por micro-ondas. Existe também a possibilidade da adição de cápsulas preenchidas com substâncias que permitem baixar a viscosidade do ligante na ocorrência de uma trinca, promovendo a sua regeneração. A seguir, serão apresentados os principais métodos de autorregeneração.

\subsection{Métodos que aceleram a autorregeneração em misturas asfálticas}

\subsubsection{Indução eletromagnética}

Os equipamentos de aquecimento por indução possuem uma tecnologia conhecida há muito tempo e atualmente são utilizados em diversas aplicações, tais como fusão ou aquecimento de metais nas indústrias e cozimento de alimentos por meio de fogóes de indução.

Conforme [9] o processo de aquecimento por indução eletromagnética se dá por meio de corrente induzida que aquece a mistura asfáltica consoante com o princípio físico de Joule (Figura 3), reduzindo a viscosidade do ligante asfáltico com o aumento de temperatura e consequentemente ocorre a fluidez do material para os vazios gerados pelas trincas. Todavia, é necessária a adição de materiais eletricamente condutivos na mistura asfáltica para induzir correntes de Foucault (corrente induzida), pois as fibras condutivas funcionam como estradas para os elétrons percorrerem.

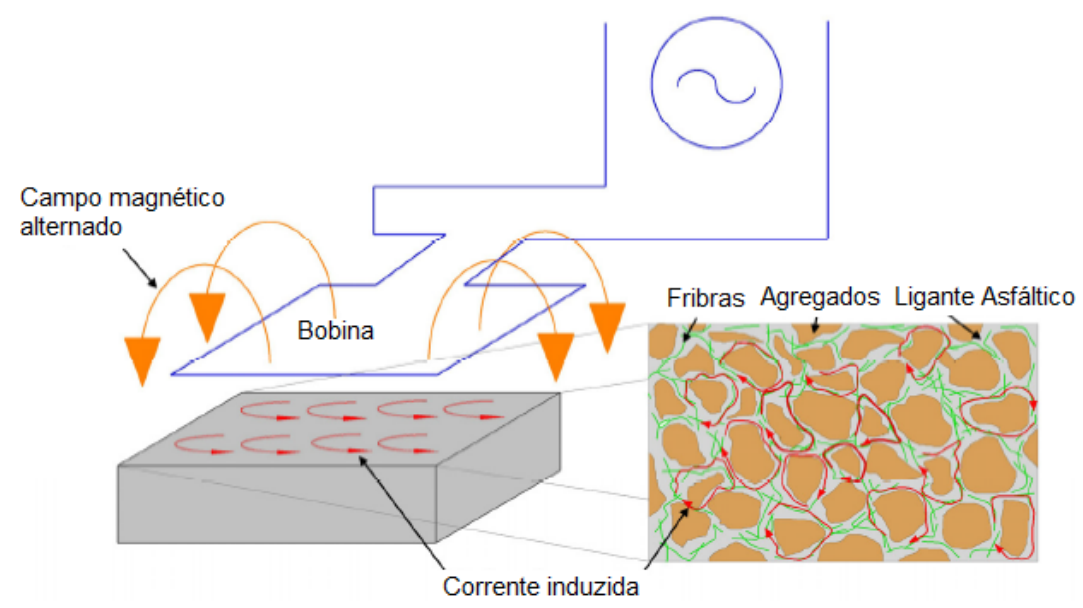

Figura 3 - Esquema de aquecimento por indução eletromagnética. Fonte: Adaptado [9]. 


\subsubsection{Irradiação de micro-ondas}

Outra maneira de elevar a temperatura do material asfáltico a fim de acelerar o processo de autorregeneração, visto que o processo é altamente dependente da temperatura, é a utilização de micro-ondas. As micro-ondas são ondas eletromagnéticas, tais como ondas de rádio, luz visível e ondas de Raios-X. A diferença entre os tipos de ondas está relacionada com o comprimento da onda. As micro-ondas têm comprimento entre $3 \mathrm{~mm}$ a $3 \mathrm{~m}$, as quais corresponde a uma frequência entre 100 $\mathrm{MHz}$ a $100 \mathrm{GHz}$. Um forno de micro-ondas típico apresenta ondas com frequência de $2.45 \mathrm{GHz}$ e comprimento de onda de $120 \mathrm{~mm}$ [10].

O processo de aquecimento por ondas eletromagnéticas consiste em adicionar partículas que promovem maior suscetibilidade da mistura asfáltica em absorver ondas eletromagnéticas, tais como fibras de aço, ferrite, grafites e escórias de siderurgia. As partículas adicionadas convertem a energia absorvida em calor, causando aquecimento do material asfáltico que ao atingir o ponto de fluidez, permitirá selar as trincas do pavimento [11]. A Figura 4 apresenta um modelo de aplicação de aquecimento por um veículo adaptado com um gerador de micro-ondas sobre um pavimento asfáltico.

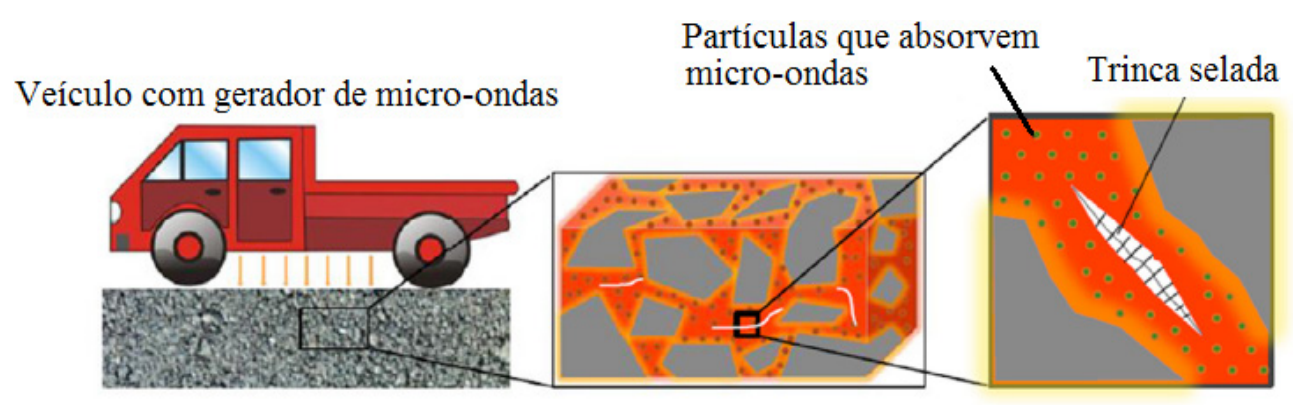

Figura 4 - Irradiação de micro-ondas em revestimento asfáltico.

Fonte: Adaptado [6].

\subsubsection{Microcápsulas}

Segundo [12], a autorregeneração com microcápsulas consiste em microcápsulas preenchidas com agentes rejuvenescedores e inseridas na mistura asfáltica. As trincas no revestimento asfáltico ao se propagarem irão atingir as microcápsulas provocando o rompimento das mesmas, conforme o esquema apresentado na Figura 5. O agente rejuvenescedor das microcápsulas fluirá para o interior das trincas dissolvendo o ligante asfáltico o qual preencherá os vazios e efetivará a recuperação das características originais do material. 


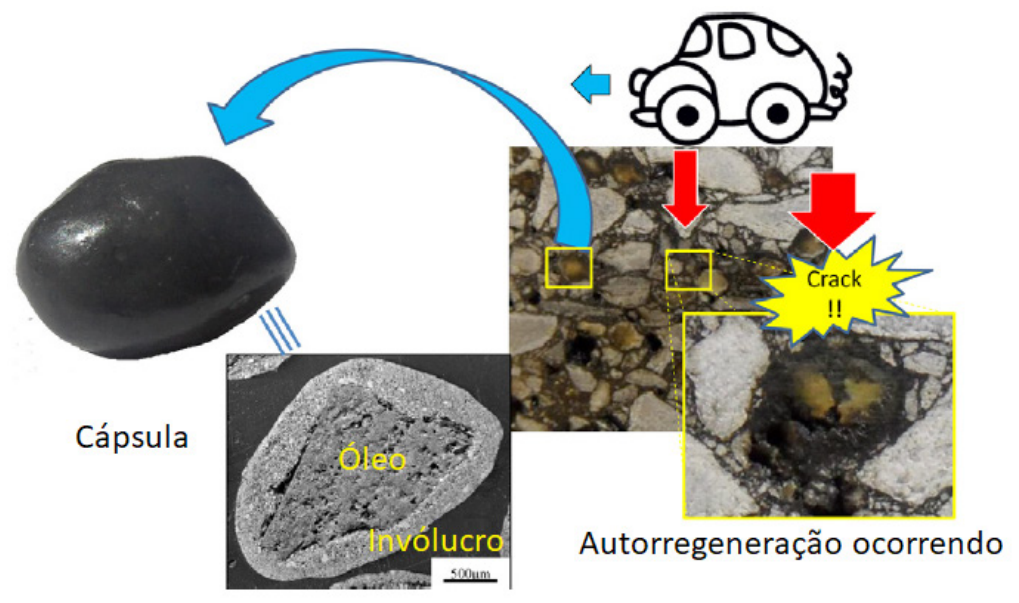

Figura 5 - Esquema de autorregeneração com cápsulas. Fonte: Adaptado [13].

Atualmente, existem dois tipos de cápsulas contendo rejuvenescedores: cápsulas com tamanho menor que $100 \mu \mathrm{m}$, que consistem em uma gota de óleo revestida por um polímero rígido; e, cápsulas com tamanho acima de $100 \mu \mathrm{m}$, as quais consistem de um núcleo poroso de areia impregnado com óleo e revestida por um invólucro rígido de enchimento e epóxi. As cápsulas na mistura asfáltica substituem fraçóes de agregados e devem resistir aos procedimentos de mistura durante a produção do material asfáltico e romperem somente na presença de trincas [13].

Muitos pesquisadores buscaram avaliar o nível de autorregeneração em misturas asfálticas, ou seja, verificar a capacidade de o material recuperar a resistência a ruptura por tensôes de fadiga ou a extensão da vida de fadiga. Assim, será apresentado no item seguinte alguns dos resultados de pesquisas que obtiveram excelentes níveis de autorregeneração em misturas asfálticas.

\subsection{Níveis de autorregeneraçáo}

[9] verificaram a taxa de regeneração de amostras de mastique asfáltico com adição de lã de aço aquecidas por indução eletromagnética. Assim, as amostras foram rompidas a $-20^{\circ} \mathrm{C}$ e aquecidas durante dois minutos até a temperatura de $120^{\circ} \mathrm{C}$; neste processo o ligante tornava-se fluído e permitia a regeneração do mastique. As amostras foram testadas por vários ciclos de rompimento e aquecimento. Após os testes, verificou-se que após o primeiro ciclo de rompimento e regeneração, a resistência média atingida foi de $90 \%$ da resistência média da amostra original, e após cinco ciclos, a resistência média foi de $70 \%$ da amostra original (Figura 6). Desta forma, os autores concluíram que é possível obter misturas asfálticas autorregenerativas, mas que o processo não é perpétuo e sua efetividade diminui a cada ciclo.

[14] obtiveram excelentes resultados ao realizarem experimentos de aquecimento por indução eletromagnética para promover a autorregeneração de trincas de fadiga em misturas de concreto 
asfáltico denso com adição de lã de aço. Os resultados da pesquisa após o sexto ciclo de fratura por tensóes de fadiga e regeneração mantiveram pelo menos a metade da resistência original. [14] também compararam a recuperação de amostras com adição de lã de aço que sofreram danos por tensões de fadiga e foram aquecidas por indução eletromagnética com amostras sem adição de lã e ficaram apenas em repouso após o ensaio de fadiga, sem o aquecimento. $\mathrm{O}$ estudo verificou uma taxa de regeneração de 100\% em misturas asfálticas contendo lá de aço e aquecidas por indução, enquanto que amostras sem adição de lã e sem aquecimento, alcançaram uma taxa de recuperação de apenas $52,08 \%$ ao ficarem em repouso.

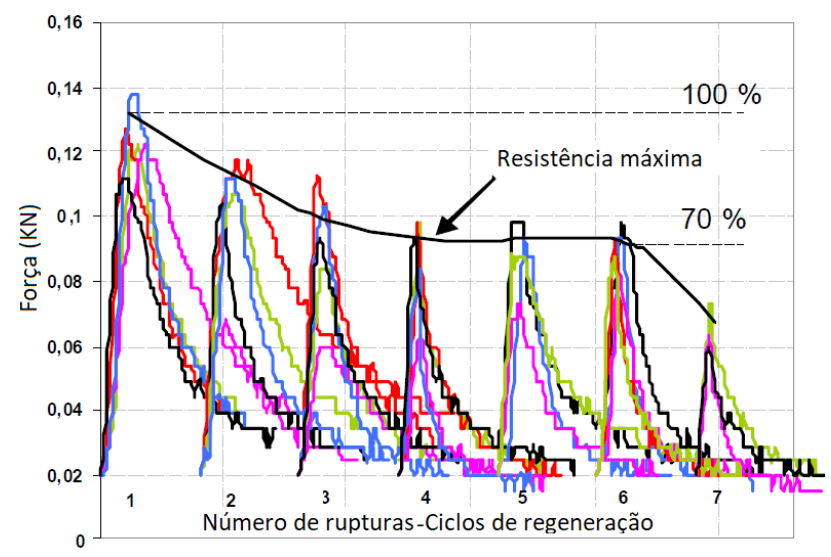

Figura 6 - Curva carga - ruptura versus ciclos de regeneração em amostras contendo 5,66\% de lã de aço (referente ao volume de ligante asfáltico) e relação de 1,60 de areia por ligante asfáltico. Fonte: Adaptado [9].

[15] verificaram o nível de regeneração de mistura asfáltica contendo $4 \%$ de fibras de aço aquecida por micro-ondas em intervalos de 40, 60, 80 e 100 segundos e concluíram que o tempo de 40 segundos de aquecimento foi o que obteve melhor nível de regeneraçáo (Figura 7).

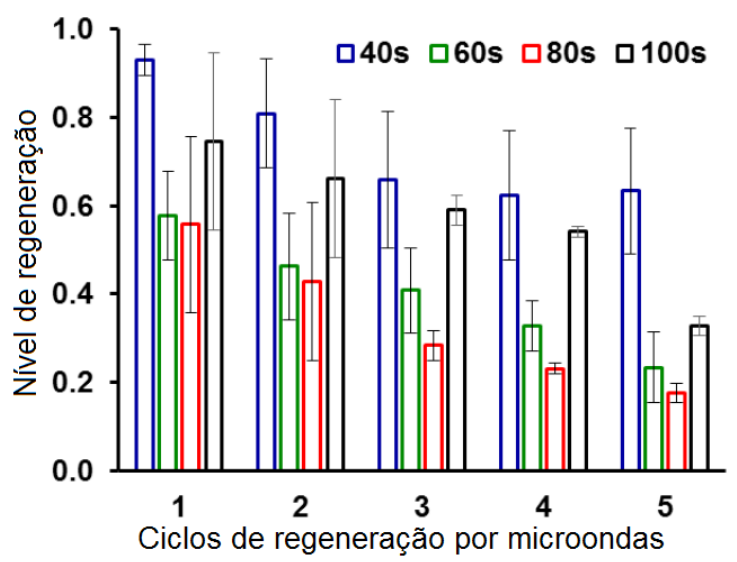

Figura 7 - Nível de regeneração em amostras aquecidas por micro-ondas em misturas asfálticas com adição de $4 \%$ de fibras de aço em função do tempo.

Fonte: Adaptado [15]. 
Segundo [6], a vida de fadiga é recuperada ao deixar em repouso misturas asfálticas que sofreram danos por tensão de fadiga, independente se foram aquecidas ou não. A recuperação dos danos ao deixar o material em repouso é maior quanto maior o tempo de descanso. Entretanto, ao aquecer o material por meio de uma fonte de energia externa, o nível de recuperação da vida de fadiga incrementa-se significativamente mesmo quando o tempo de repouso do material é curto. A seguir são apresentadas alguns dos resultados de pesquisas no quadro resumo da Tabela 1:

Tabela 1 - Quadro resumo de pesquisas com misturas asfálticas autorregenerativas.

\begin{tabular}{|c|c|c|c|c|c|}
\hline Técnica & Mistura asfáltica & Parâmetro & $\begin{array}{l}\text { Número } \\
\text { de ciclos }\end{array}$ & $\begin{array}{c}\text { Nível de } \\
\text { autorregeneração }\end{array}$ & Ref. \\
\hline $\begin{array}{c}\text { Indução } \\
\text { eletromagnética }\end{array}$ & $\begin{array}{l}\text { Mástique asfáltico } \\
\text { com } 5,66 \% \text { de lã } \\
\text { de aço }\end{array}$ & $\begin{array}{l}\text { Resistência máxima a tração - Não } \\
\text { especifica o tipo de ensaio. }\end{array}$ & 7 & $\begin{array}{l}90 \% \text { no } 1^{\circ} \text { ciclo e } \\
70 \% \text { após o } 5^{\circ} \text { ciclo }\end{array}$ & [9] \\
\hline $\begin{array}{c}\text { Indução } \\
\text { eletromagnética }\end{array}$ & $\begin{array}{c}\text { Concreto asfáltico } \\
\text { denso com } 8 \% \text { lã } \\
\text { de aço }\end{array}$ & $\begin{array}{l}\text { Resistência máx. a tração - Ensaio } \\
\text { de flexão em viga de } 3 \text { pontos } \\
\text { (deformação controlada, } 5 \mathrm{~mm} / \mathrm{min} \text { ) }\end{array}$ & 9 & $\begin{array}{l}100 \% \text { após o } 1^{\circ} \text { ciclo } \\
\text { e } 50 \% \text { após o } 6^{\circ} \\
\text { ciclo }\end{array}$ & {$[14]$} \\
\hline Micro-ondas & $\begin{array}{l}\text { Concreto asfáltico } \\
\text { denso com } 4 \% \text { de } \\
\text { fibras de aço }\end{array}$ & $\begin{array}{l}\text { Resistência máx. a tração - Ensaio } \\
\text { de flexão em viga de } 3 \text { pontos } \\
\text { (deformação controlada, } 5 \mathrm{~mm} / \mathrm{min} \text { ) }\end{array}$ & 5 & $\begin{array}{l}93 \% \text { após o } 1^{\circ} \text { ciclo } \\
\text { ao aquecer por } 40 \\
\text { seg. e } 62 \% \text { após o } 5^{\circ} \\
\text { ciclo }\end{array}$ & {$[15]$} \\
\hline
\end{tabular}

Fonte: Os autores (2017).

\section{Conclusóes}

A autorregeneração em misturas asfálticas foi validada por diversas pesquisas e que comprovaram que é possível estender a vida de serviço de pavimentos asfálticos que sofreram danos por tensóes de fadiga, desde que estes danos não causem deformações permanente no material.

A autorregeneração em misturas asfálticas é altamente dependente da temperatura do ligante asfáltico, dessa forma a fim de acelerar o processo de regeneração, o aquecimento de misturas asfálticas contendo materiais condutivos por indução eletromagnética ou por micro-ondas tem apresentado ótimos resultados. Há ainda a adição microcápsulas preenchidas com agentes rejuvenescedores durante a produção da mistura asfáltica que liberam o agente apenas quando o revestimento asfáltico apresentar trincas. Ademais, a autorregeneração de misturas asfálticas é influenciada por diversos fatores, tais como o tipo de ligante asfáltico, o tempo em repouso, das dimensôes das trincas, do tipo de material condutivo adicionado na mistura, da quantidade de material condutivo adicionado, das propriedades físicas do material e entre outros fatores. Apesar da efetividade de regeneração ser reduzida a cada ciclo (danos seguidos de regeneração), ainda é possível obter bons resultados durante os primeiros ciclos de regeneração, tal como os resultados de [6] que alcançaram $70 \%$ da resistência original até o sexto ciclo de regeneração. 
Porém, ainda restam muitas lacunas no desenvolvimento de misturas asfálticas autorregenerativas que necessitam ser estudadas com maior aprofundamento, tais como as aplicaçóes em campo com o desenvolvimento de equipamentos de aquecimento para serem utilizados em rodovias. Deve-se, ainda, avaliar as propriedades mecânicas das misturas asfálticas com os diversos tipos de adiçôes suscetíveis ao aquecimento, as características dos materiais condutivos adicionados em mistura asfálticas e os fatores que influenciam no revestimento asfáltico devido ao processo de autorregenração. Outro ponto que necessita ser avaliado são os tipos de misturas asfálticas existentes no mercado e os níveis de autorregeneração possíveis de serem alcançados.

\section{Referências}

[1] BALBO, J. T. Pavimentaçáo Asfáltica: materiais, projetos e restauração. São Paulo: Oficina de Textos, 2007.

[2] BRASIL. DEPARTAMENTO NACIONAL DE INFRA-ESTRUTURA DOS TRANSPORTES - DNIT. Manual de Restauraçáo de Pavimentos Asfáltico. 2.ed. Rio de Janeiro, 2006. 310p

[3] ASPHALT INSTITUTE. Disponível em: < http://www.asphaltinstitute.org/asphalt-pavement-distress-summary/> Acesso em: 14 de nov. 2017.

[4] CONFEDERAÇĀO NACIONAL DO TRANSPORTE - CNT. Pesquisa CNT de rodovias 2016: relatório gerencial. 20. ed. Brasília: CNT: SEST: SENAT, 2016. Disponível em: < http://pesquisarodoviascms.cnt.org.br/ Relatorio\%20Geral/Pesquisa\%20CNT\%20(2016)\%20-\%20LOW.pdf> Acesso em: 3 de abr. 2017.

[5] AYAR, P.; NAVARRO, F. M.; GÁMEZ, M. C. R. The healing capability of asphalt pavements: a state of the art review. Cleaner Production, 113, p. 28-40, 2016. Disponível em < http://www.sciencedirect.com/science/article/pii/ S0959652615018582 >. Acesso em: 8 out. 2017.

[6] ZHU, X.; CAI, Y.; ZHONG, S.; ZHU, J.; ZHAO, H. Self-healing efficiency of ferrite-filled asphalt mixture after microwave Irradiation. Construction and Building Materials, v. 141, 2017. p. 12-22. Disponível em:<http://www. sciencedirect.com/science/article/pii/S095006181730346X>. Acesso em: 26 ago. 2017.

[7] LIU, Q.; GARCÍA, A.; SCHLANGEN, E.; VEN, M. V. Induction healing of asphalt mastic and porous asphalt concrete. Construction and Building Materials, v.25, p.3746-3752, abr. 2011. Disponível em: < https://www. researchgate.net/publication/229439179>. Acesso em: 25 mar. 2017.

[8] MENOZZI, A.; GARCÍA, A.; PARTL, M. N.; SCHUETZ, P. Induction healing of fatigue damage in asphalt test samples. Construction and Building Materials, v.74, p. 162-168. 2015. Disponível em:< https://www.researchgate. net/publication/267928694>. Acesso em: 31 mar. 2017.

[9] GARCÍA, A.; SCHLANGEN, E.; VEN, M. V.; VLIET, D. V. Crack repair of asphalt concrete with induction energy. Heron, v. 56, 2011. Disponível em:<https://www.researchgate.net/publication/236683573>. Acesso em: 24 mar. 2017.

[10] GALLEGO, J.; VAL, M. A.; CONTRERAS, V.; PÁEZ, A. Heating asphalt mixtures with microwaves to promote self-healing. Construction and Building Materials, v. 42, p.1-4, 2013. Disponível em: < http://www.sciencedirect. com/science/article/pii/S0950061812009634>. Acesso em: 14 jul. 2017.

[11] CONTRERAS, J. N.; GARCIA, A. Effect of fibres addition on the physical and mechanical properties of asphalt mixtures with crack-healing purposes by microwave radiation. Materials \& design, v. 106, p. 404-414, 2016. Disponível em: <http://www.sciencedirect.com/science/article/pii/S0264127516307006>. Acesso em: 19 abr. 2017.

[12] CHUNG, K; LEE, S.; PARK, M.; YOO, P.; HONG, Y. K. Preparation and characterization of microcapsulecontaining self-healing asphalt. Journal of Industrial and Engineering Chemistry, v. 29, p. 330 -337, 2015.

Disponível em: < http://www.sciencedirect.com/science/article/pii/S1226086X15001409>. Acesso em: 11 out. 2017.

[13] GARCÍA, A.; JELFS, J.; AUSTIN, C. J. Internal asphalt mixture rejuvenation using capsules. Construction and Building Materials, v.101, p.309-316, 2015. Disponível em: < http://www.sciencedirect.com/science/article/pii/ S0950061815304839>. Acesso em: 7 nov. 2017. 
[14] DAI, Q.; WANG, Z.; HASAN, M. R. M. Investigation of induction healing effects on electrically conductive asphalt mastic and asphalt concrete beams through fracture-healing tests. Construction and Building Materials, v. 49, p.729-737, 2013. Disponível em: < http://www.sciencedirect.com/science/article/pii/ S0950061813008325>. Acesso em: 14 abr. 2017.

[15] CONTRERAS, J. N.; GARCÍA, A. Self-healing of asphalt mixture by microwave and induction heating. Construction and Building Materials, v. 127, p. 369-382, 2016. Disponível em: <http:/www.sciencedirect.com/ science/article/pii /S0950061816316099>. Acesso em: 25 jul. 2017. 